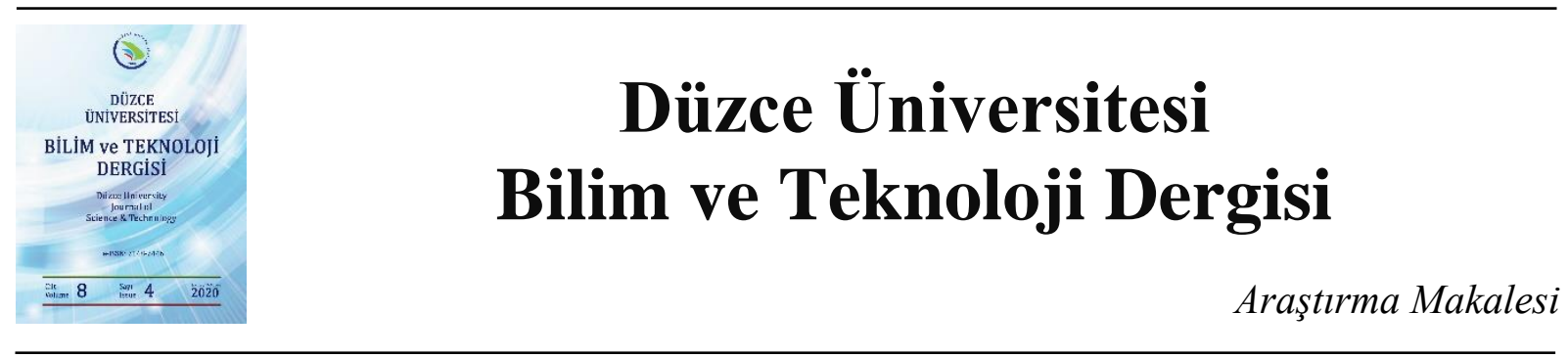

\section{Basınç Elemanları İçin Yardımcı Abaklar}

\author{
Mehmet Bakır BOZKURT ${ }^{\mathrm{a}, *}$ \\ ${ }^{a}$ İnşaat Mühendisliği Bölümü, Mühendislik Fakültesi, Manisa Celal Bayar Üniversitesi, Manisa, TÜRKİYE \\ * Sorumlu yazarın e-posta adresi: mehmet.bozkurt@cbu.edu.tr \\ DOI : 10.29130/dubited.734643
}

\begin{abstract}
ÖZET
$\mathrm{Bu}$ çalışma yapısal tasarımcıların sıcak haddelenmiş I-enkesitli profillerden teşkil edilmiş basınç elemanlarını Çelik Yapıların Tasarım, Hesap ve Yapım Esasları'na (ÇYTHYE'na) göre hızlı ve etkin bir şekilde boyutlandırılabilmeleri için yardımcı abaklar sunmaktadır. Bu amaç için ÇYTHYE'de tanımlanan yük ve dayanım katsayıları ile tasarım (YDKT) esaslarına göre uygulamada en çok tercih edilen S235, S275 ve S355 malzeme sınıflarından teşkil edilmiş HEA, HEB, IPE ve IPN profilleri için ayrı ayrı basınç taşıma kapasiteleri belirlenmiş ve narinlik değerlerine göre değişimlerini gösteren abaklar oluşturulmuştur. Hazırlanan bu abaklar sayesinde malzeme sınıfına ve enkesit tipine göre istenilen narinlik değerlerinde elemanların tasarım basınç kuvveti dayanımlarına ulaşıla bilinecektir.
\end{abstract}

Anahtar Kelimeler: ÇYTHYE, Çelik, Yönetmelik, Basınç elemanı, Abak.

\section{Supplementary Nomograms for Compression Members}

\begin{abstract}
This study presents supplementary nomograms for the structural designers in order to design the hot-rolled Ishaped compression members based on Specification for Design, Calculation and Construction of Steel Structures (SDCCSS) so that they are able to be designed quickly and efficiently. Pursuant this aim, the compression capacities of the HEA, HEB, IPE and IPN sections made of S235, S275 and S355 material classes designed based on load and resistance factor design (LRFD) defined in SDCCSS were determined and the nomograms indicating their variation with respect to their slenderness were conducted. Thanks to these nomograms prepared, the design compressive force strengths of the elements can be achieved according to the material class and cross section type at the desired slenderness values.
\end{abstract}

Keywords: SDCCSS, Steel, Specification, Compression member, Nomogram

Geliş: 09/05/2020, Düzeltme: 13/10/2020, Kabul: 19/10/2020 


\section{GIRIS}

Çelik yapıların tasarımında ihtiyaç duyulan gerekli dayanım, stabilite ve yerdeğiştirme tahkikleri için ulusal veya uluslararası yönetmelikler kullanılır. Amerika Birleşik Devletleri'nde kullanılan "Specification for Structural Steel Buildings, ANSI/AISC 360-16" [1] ve Avrupa'da kullanilan "Eurocode 3: Design of steel structures (EN 1993)" [2] bilinen en yaygın uluslararası çelik tasarım yönetmelikleridir. Diğer taraftan Kanada'da "Design of Steel Structures, CSA S16:19" [3] ve Japonya'da "Standard Specifications for Steel and Composite Structures, JSCE-2007" [4] yönetmelikleri ise çelik yapıların tasarımı için kullanılan diğer uluslararası yönetmeliklerdir.

Türkiye'de çelik yapıların tasarımı için 1980 yılından 2016 yılına kadar "Çelik Yapıların Hesap ve Yapım Kuralları, TS 648" [5] kullanılmasına rağmen 2016 yılından itibaren "Çelik Yapıların Tasarım, Hesap ve Yapımına Dair Esaslar, ÇYTHYE" [6] kullanılmaktadır. TS 648'den [5] farklı olarak ÇYTHYE [6] tasarımcılara temeli hem taşıma gücü ilkelerine dayanan Yük ve Dayanım Katsayıları ile Tasarım (YDKT) hem de emniyet gerilmesi ilkelerine dayanan Güvenlik Katsayıları ile Tasarım (GKT) yöntemlerinin kullanılmasına olanak sağlamaktadır.

Yapısal tasarımcılar çelik elemanların boyutlandırılmasında tasarım yönetmeliklerinin yanı sıra birçok yardımcı tablo ve abaklara ihtiyaç duyarlar. "Steel Construction Manual" [7] Amerika pratiğinde, "Steel Building Design: Design Data" [8], "Joints in Steel Construction: Simple Joints To Eurocode 3" [9] ve "Joints in Steel Construction: Moment-Resisting Joints To Eurocode 3" [10] Avrupa pratiginde kullanılan en önemli yardımcı dokümanlardır.

Türkiye'de TS 648 [5] için herhangi bir yardımcı tasarım dokümanı bulunmamasına rağmen, Çevre ve Şehircilik Bakanlığı, ÇYTHYE [6] ile beraber "Çelik Yapıların Tasarım, Hesap ve Yapım Esaslarına Dair Yönetmelik Hakkında Uygulama Kılavuzu" [11] dokümanını yayınlayarak tasarımcıların hizmetine sunmuştur. Bu doküman [11] eleman boyutlandırılması için özet bilgiler ve sayısal uygulamalar içermesine rağmen, münferit elemanların boyutlandırılması için yardımcı tablolar ve abaklar sunmamaktadır. Bu çalışma, ÇYTHYE'de [6] tanımlanan YDKT esaslarına göre basınç elemanların boyutlandırılması için yardımcı abaklar sunmaktadır. Tasarımcıların sıklıkla kullanacakları bu abaklar sayesinde S235, S275 ve S355 malzeme sınıflarından teşkil edilmiş ve sicak haddenmiş Ienkesitli HEA, HEB, IPE ve IPN elemanların tasarımları hızlı ve etkin bir şekilde gerçekleşebilecektir.

\section{BASINC ELEMANLARININ BOYUTLANDIRMA ESASLARI}

Eksenel basınç kuvvetine maruz kalan elemanların dayanım sınır durumlarını enkesit parçalarının genişlik/kalınlık oranlarına göre tanımlanan lokal veya global burkulma dayanımları belirler. ÇYTHYE [6] hadde I-enkesitli profillerin rijitleştirilmemiş enkesit parçasını oluşturan başlık parçaları için Denklem (1)'de tanımlanan sınır narinlik değerini ve rijitleştirilmiş enkesit parçasını oluşturan gövde parçası için Denklem (2)'de tanımlanan sınır narinlik değerini kullanarak kesit sınıflandırması yapar.

$$
\begin{aligned}
& \lambda=\frac{b_{f}}{2 t_{f}} \leq \lambda_{r}=0.56 \sqrt{\frac{E}{F_{y}}} \\
& \lambda=\frac{h}{t_{w}} \leq \lambda_{r}=1.49 \sqrt{\frac{E}{F_{y}}}
\end{aligned}
$$

Burada, $\mathrm{b}_{f}$ ve $\mathrm{t}_{f}$ profil başlık genişliği ve kalınlığı, $h$ ve $t_{w}$ profil gövde yüksekliği ve kalınlığıdır. $E$ ve $F_{y}$ ise yapısal çeliğin elastisite modülü ve akma gerilmesidir. 
ÇYTHYE [6] esaslarına göre karakteristik basınç kuvveti dayanımı, $P_{n}$ kritik burkulma gerilmesi, $F_{c r}$ ile kayıpsız enkesit alanı, $A_{g}$ 'nin çarpılması ile elde edilir. Eğer hadde I-enkesiti oluşturan başlık veya gövde enkesit parçaları yukarıda tanımlanan sınır narinlik durumlarını aşıyorlarsa karakteristik basınç kuvveti dayanımı hesabında kayıpsız enkesit alan $A_{g}$ yerine etkin enkesit alan $A_{e}$ kullanılır. Diğer taraftan tasarım basınç kuvveti dayanımı için karakteristik dayanım 0.9 ile çarpılırken, güvenli basınç kuvveti dayanımı için 1.67 güvenlik faktörüne bölünür.

Narin olmayan enkesitler için $\quad P_{n}=F_{c r} A_{g}$

Narin enkesitler için

$$
P_{n}=F_{c r} A_{e}
$$

Burada, $F_{c r}$ kritik burkulma gerilmesidir. Etkin enkesit alanı $A_{e}$ 'nin hesaplanması aşağıda tanımlanan etkin başlık genişliği ve/veya etkin gövde yüksekliği be'nin tespiti ile belirlenir.

$$
\begin{array}{ccc}
b & \text { eger } & \lambda \leq \lambda_{r} \sqrt{\frac{F_{y}}{F_{c r}}} \\
b_{e}= & \text { eger } & \lambda>\lambda_{r} \sqrt{\frac{F_{y}}{F_{c r}}} \\
F_{e l}=\left(1-c_{1} \sqrt{\frac{F_{e l}}{F_{c r}}}\right) \sqrt{\frac{F_{e l}}{F_{c r}}} & \left.\lambda_{r}\right)^{2} F_{y} &
\end{array}
$$

Burada, $b$ ve $b_{e}$ enkesit parçasının ve etkin enkesit parçasının genişliği, $c_{1}$ ve $c_{2}$ etkin genişlik hata düzeltme katsayısıdır ve başlık enkesit parçaları için sırasıyla 0.22 ve 1.49 , gövde enkesit parçaları için sırasıyla 0.18 ve 1.31 değerlerine eşittir. $F_{e l}$ yerel elastik burkulma gerilmesidir ve Denklem (6) kullanılarak hesaplanır.

Eksenel basınç kuvvetine maruz kalan elemanların kritik burkulma göçmeleri enkesit geometrisine bağlı olarak eğilmeli, burulmalı veya eğilmeli-burulmalı burkulma şeklinde gerçekleşebilir. Çift simetri eksene sahip hadde I-profiller için hâkim kritik burkulma eğilmeli burkulma göçmesidir. Eksenel basınç kuvvetine maruz kalan çelik elemanların tipik dayanım eğrisi Şekil 1'de ve ilgili formüller Denklem (5) ve Denklem (6)'da verilmiştir.

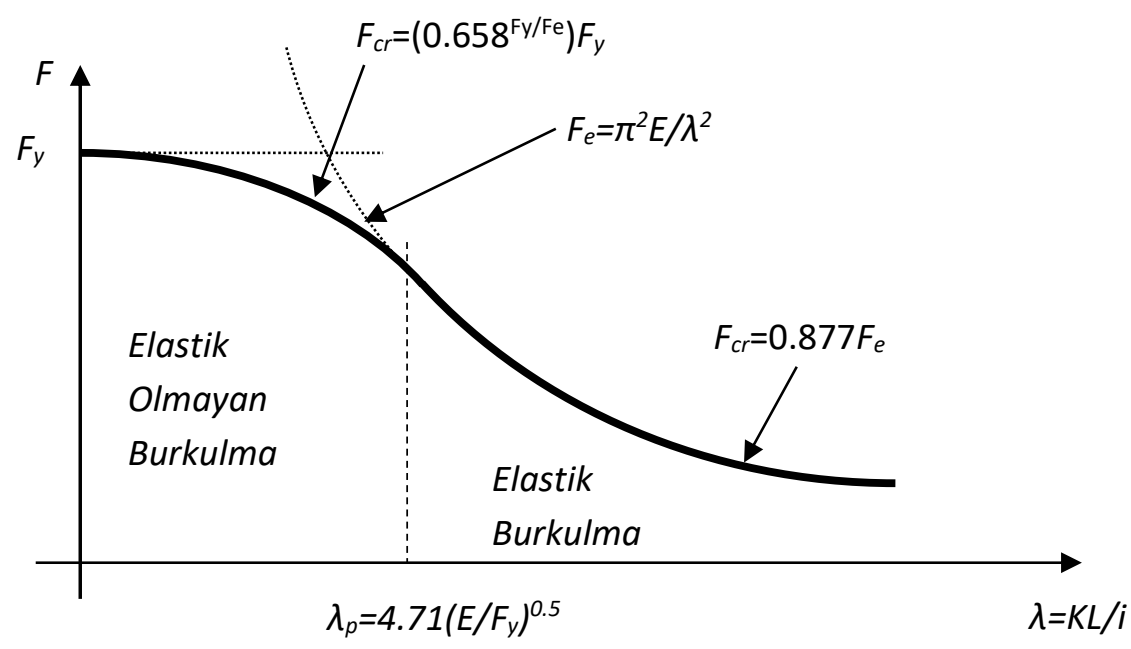

Şekil 1. Eksenel basinç kuvvetine maruz kalan çelik elemanların tipik dayanım eğrisi [11] 


$$
\begin{array}{rlrl}
F_{c r}= & \text { eger } & \frac{K L}{i} \leq 4.71 \sqrt{\frac{F_{y}}{F_{y}}} \\
0.877 F_{e} & \text { eger } & \frac{K L}{i}>4.71 \sqrt{\frac{E}{F_{y}}} \\
F_{e}=\frac{\pi^{2} E}{\left(\frac{K L}{i}\right)^{2}} &
\end{array}
$$

Burada, $K$ burkulma boyu katsayısı, $i$ atalet yarıçapı, $L$ desteklenen noktalar arasında kalan eleman uzunluğu ve $F_{e}$ elastik burkulma gerilmesidir.

ÇYTHYE'de [6] tanımlanan YDKT esaslarına göre S235, S275 ve S355 malzeme sınıflarından teşkil edilmiş HEA profillerinin tasarım basınç kuvveti dayanımlarının narinlik değerlerine göre değişimleri sırasıyla Şekil 2, Şekil 3 ve Şekil 4'de, HEB profillerinin Şekil 5, Şekil 6 ve Şekil 7'de, IPE profillerinin Şekil 8, Şekil 9 ve Şekil 10'da, IPN profillerinin ise Şekil 11, Şekil 12 ve Şekil 13'de gösterilmiştir. 


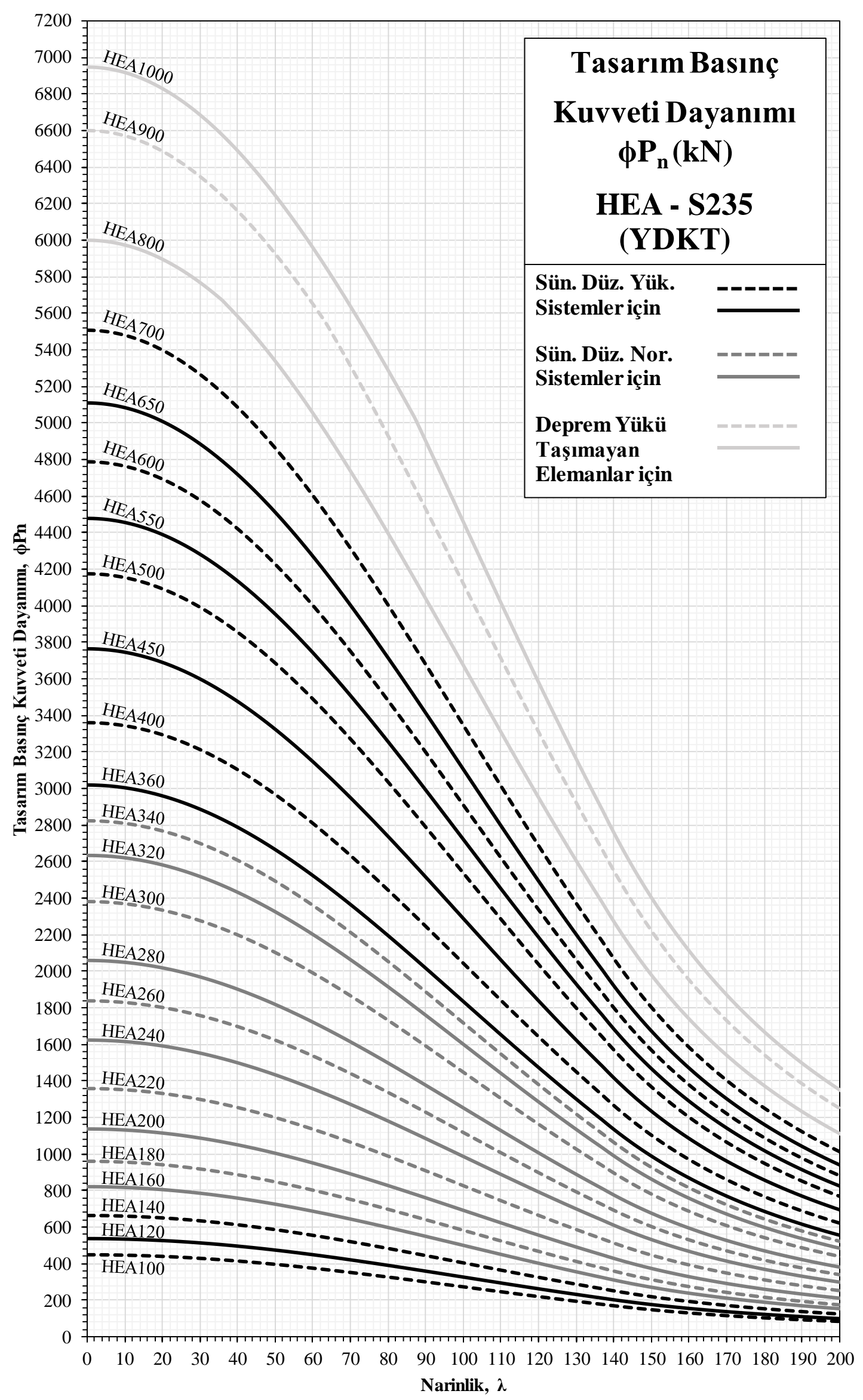

Şekil 2. S235 malzeme ve HEA enkesitlerine ait tasarım basınç kuvveti dayanımları 


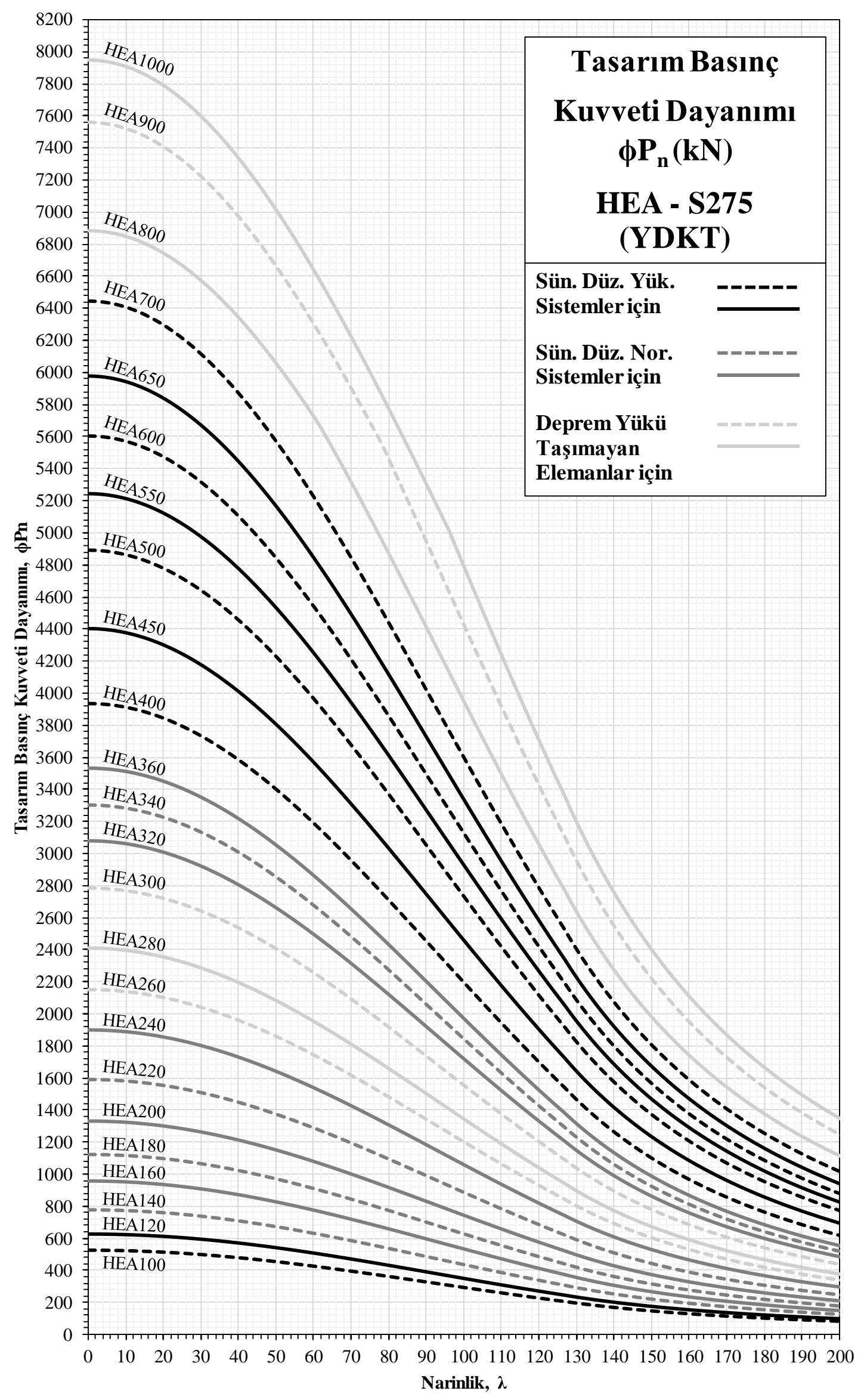

Şekil 3. S275 malzeme ve HEA enkesitlerine ait tasarım basınç kuvveti dayanımları 


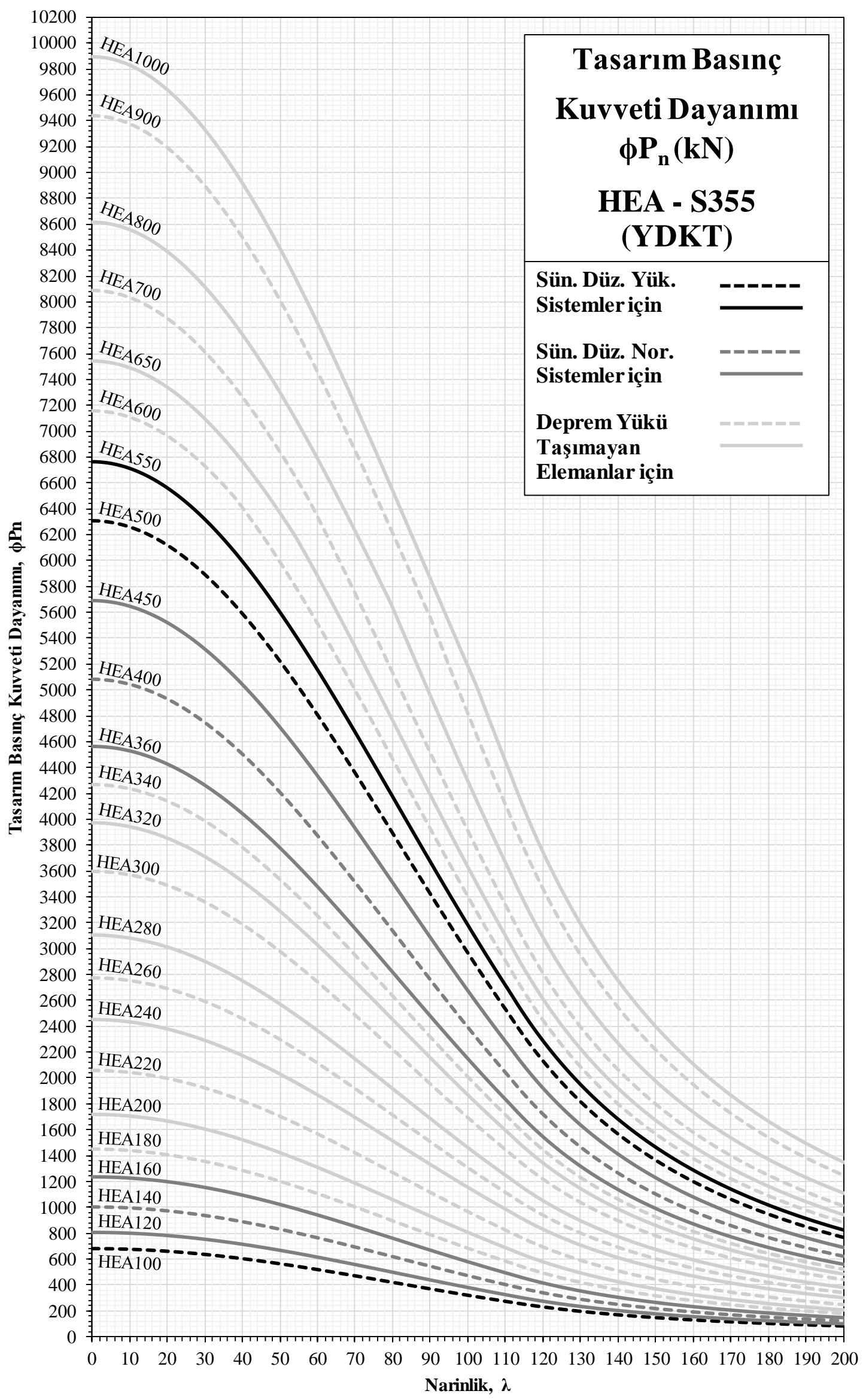

Şekil 4. S355 malzeme ve HEA enkesitlerine ait tasarım basınç kuvveti dayanımları 


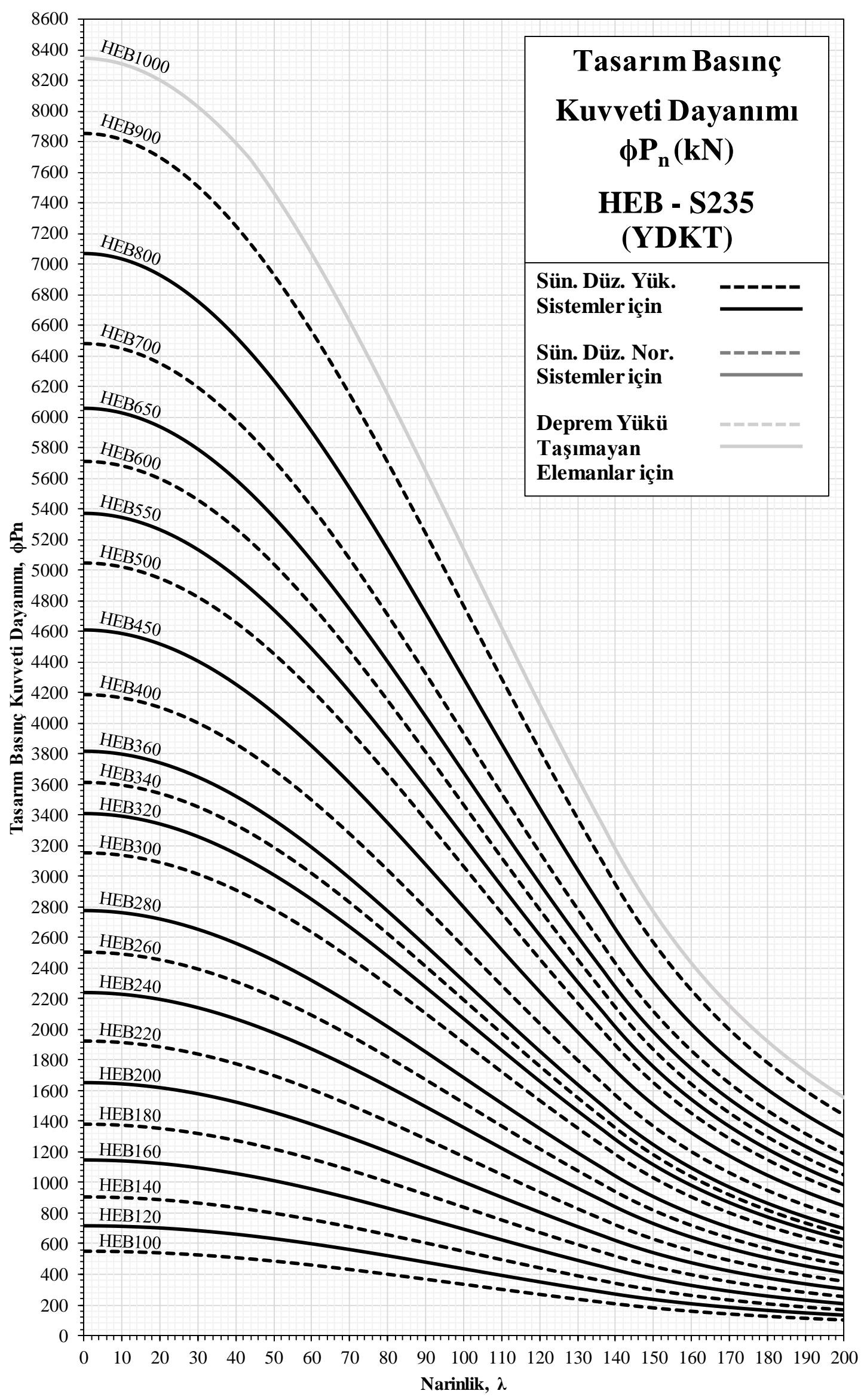

Şekil 5. S235 malzeme ve HEB enkesitlerine ait tasarım basınç kuvveti dayanımları 


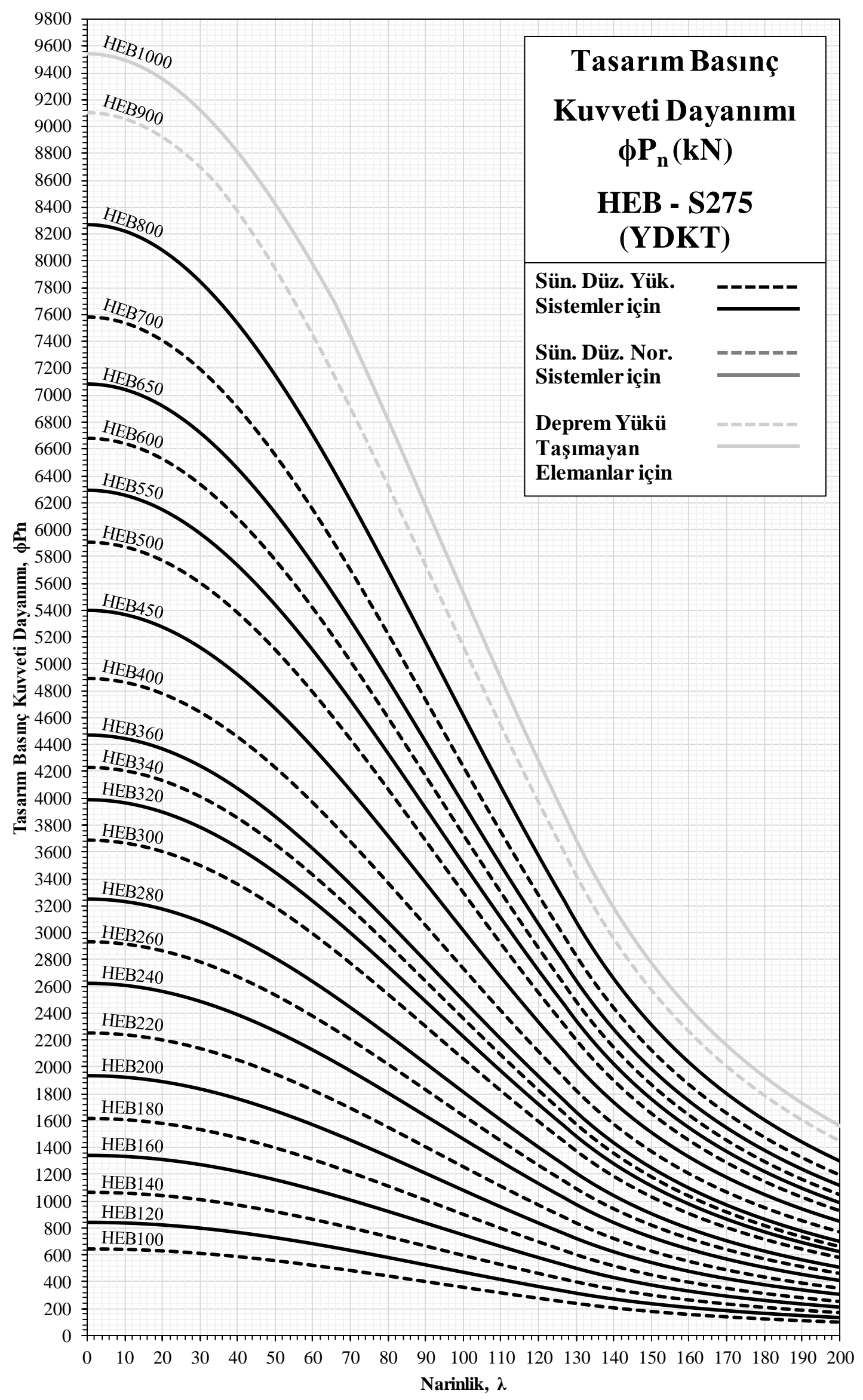

Şekil 6. S275 malzeme ve HEB enkesitlerine ait tasarım basinç kuvveti dayanımları 


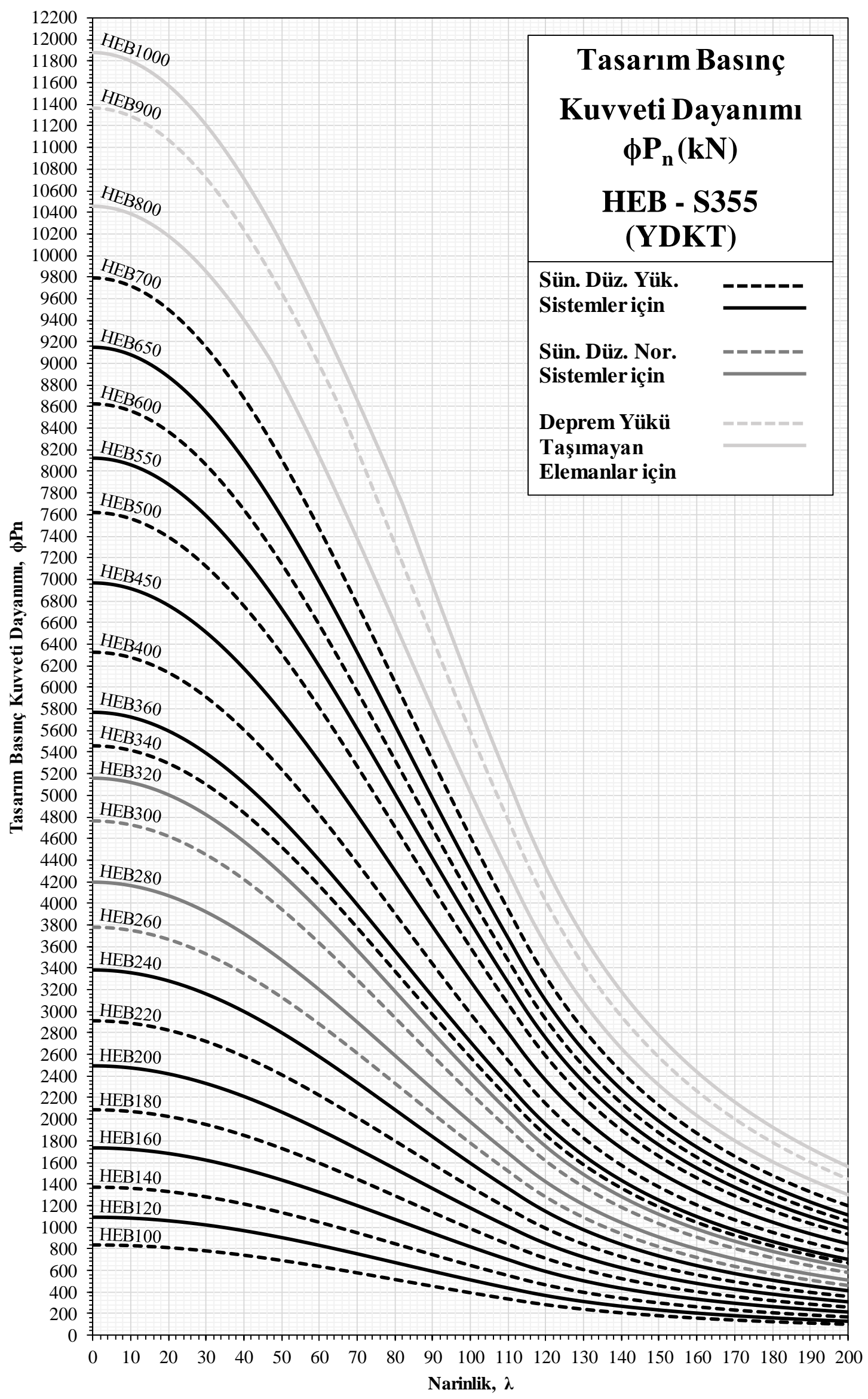

Şekil 7. S355 malzeme ve HEB enkesitlerine ait tasarım basınç kuvveti dayanımları 


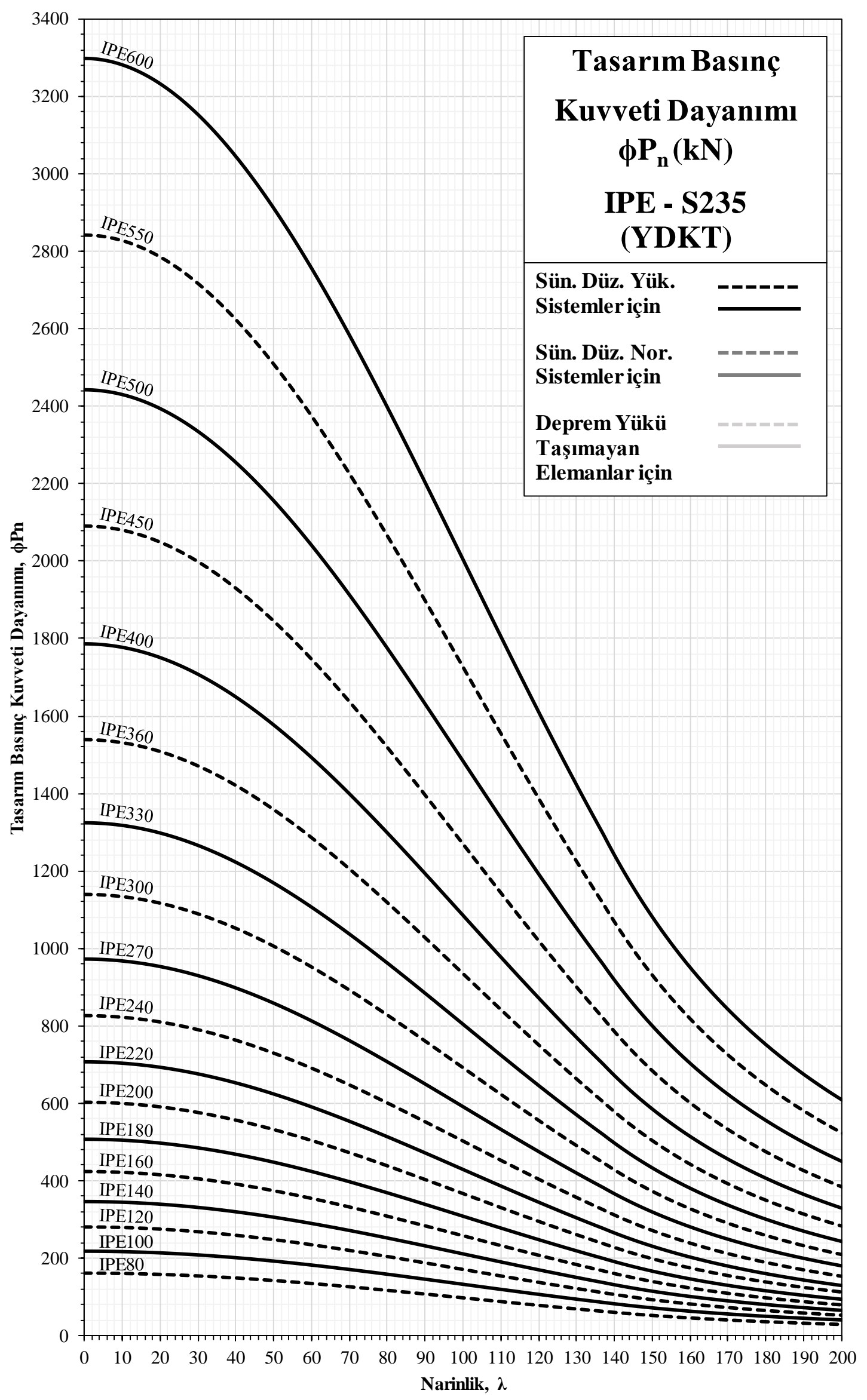

Şekil 8. S235 malzeme ve IPE enkesitlerine ait tasarım basınç kuvveti dayanımları 


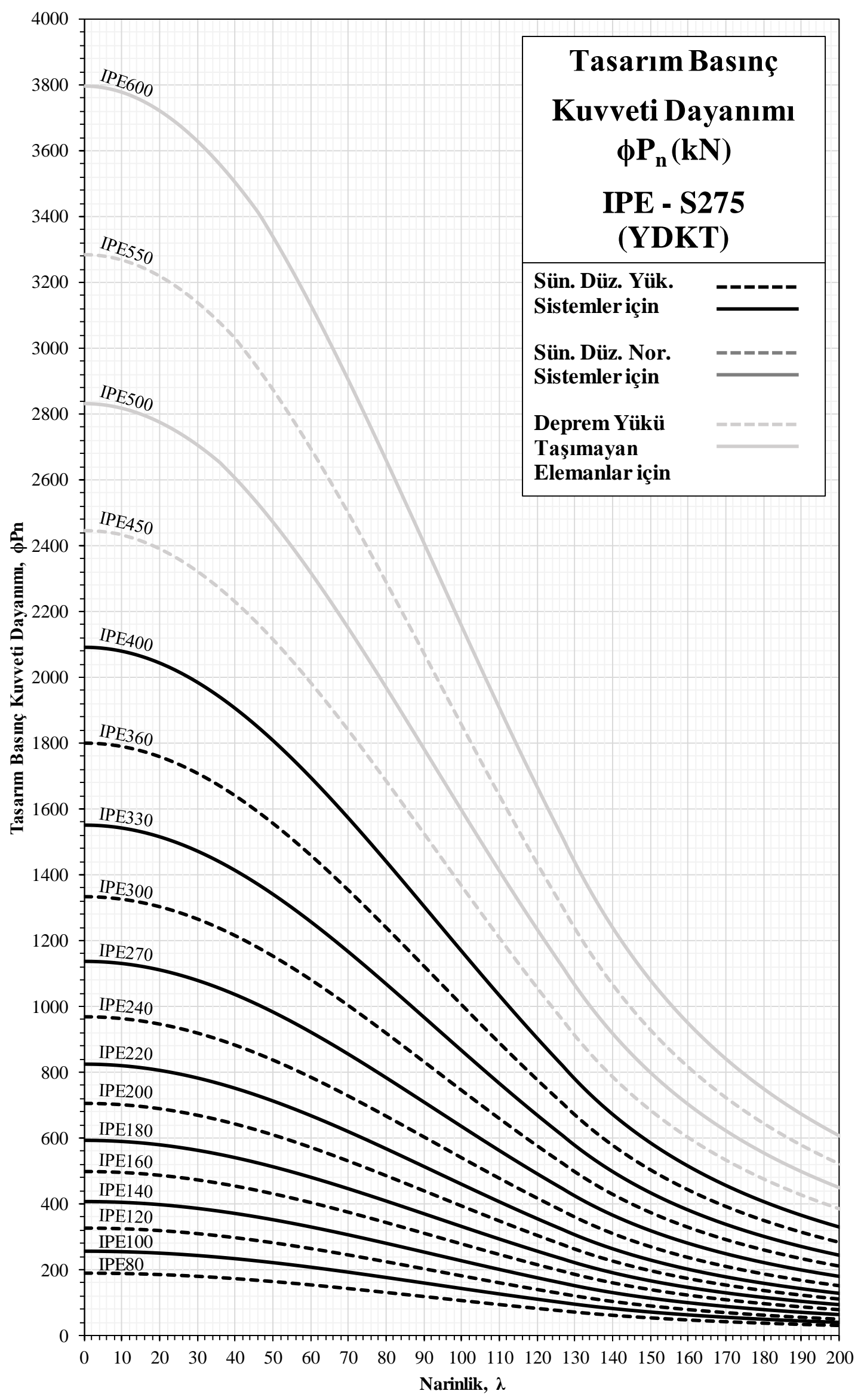

Şekil 9. S275 malzeme ve IPE enkesitlerine ait tasarım basınç kuvveti dayanımları 


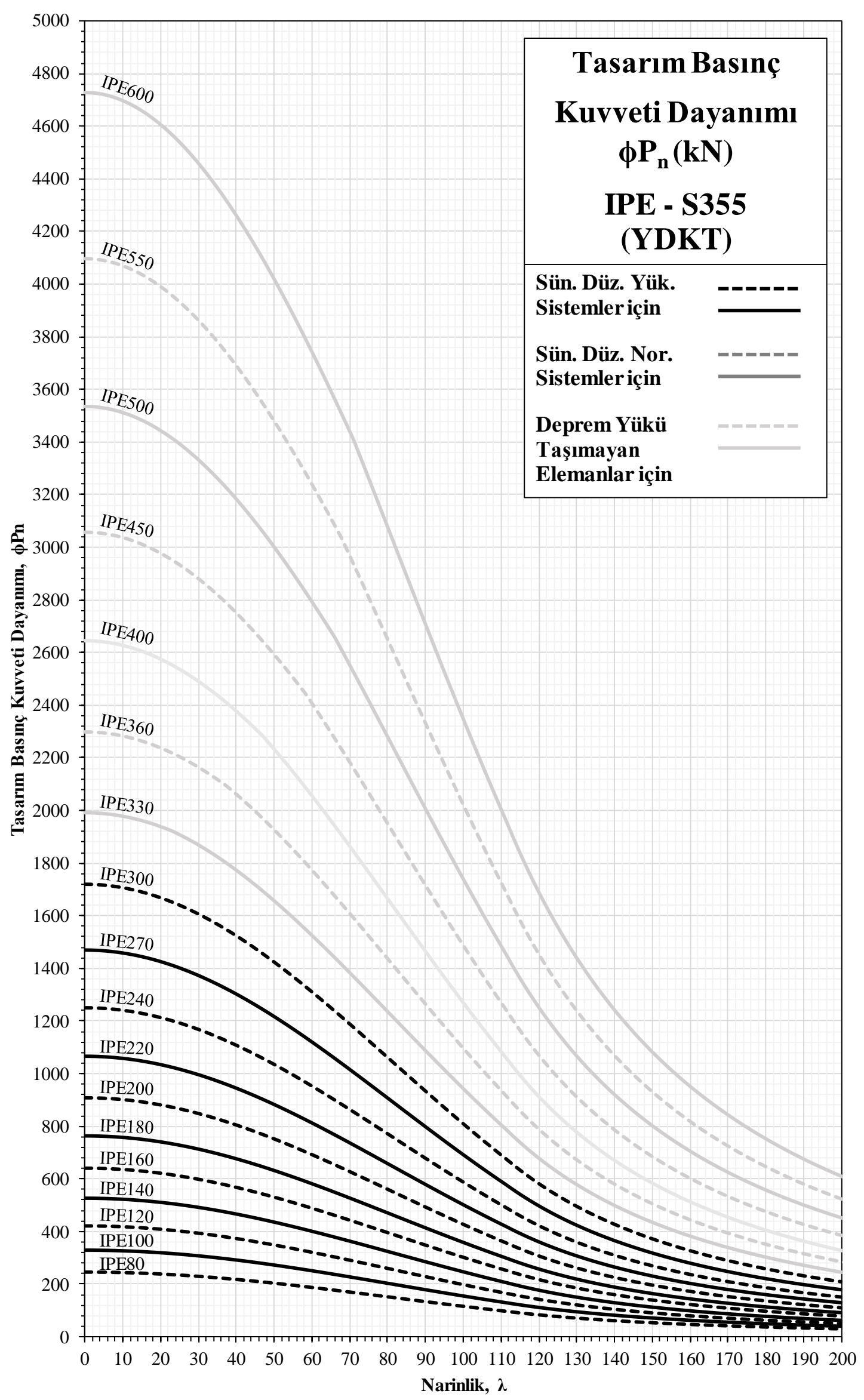

Şekil 10. S355 malzeme ve IPE enkesitlerine ait tasarım basınç kuvveti dayanımları 


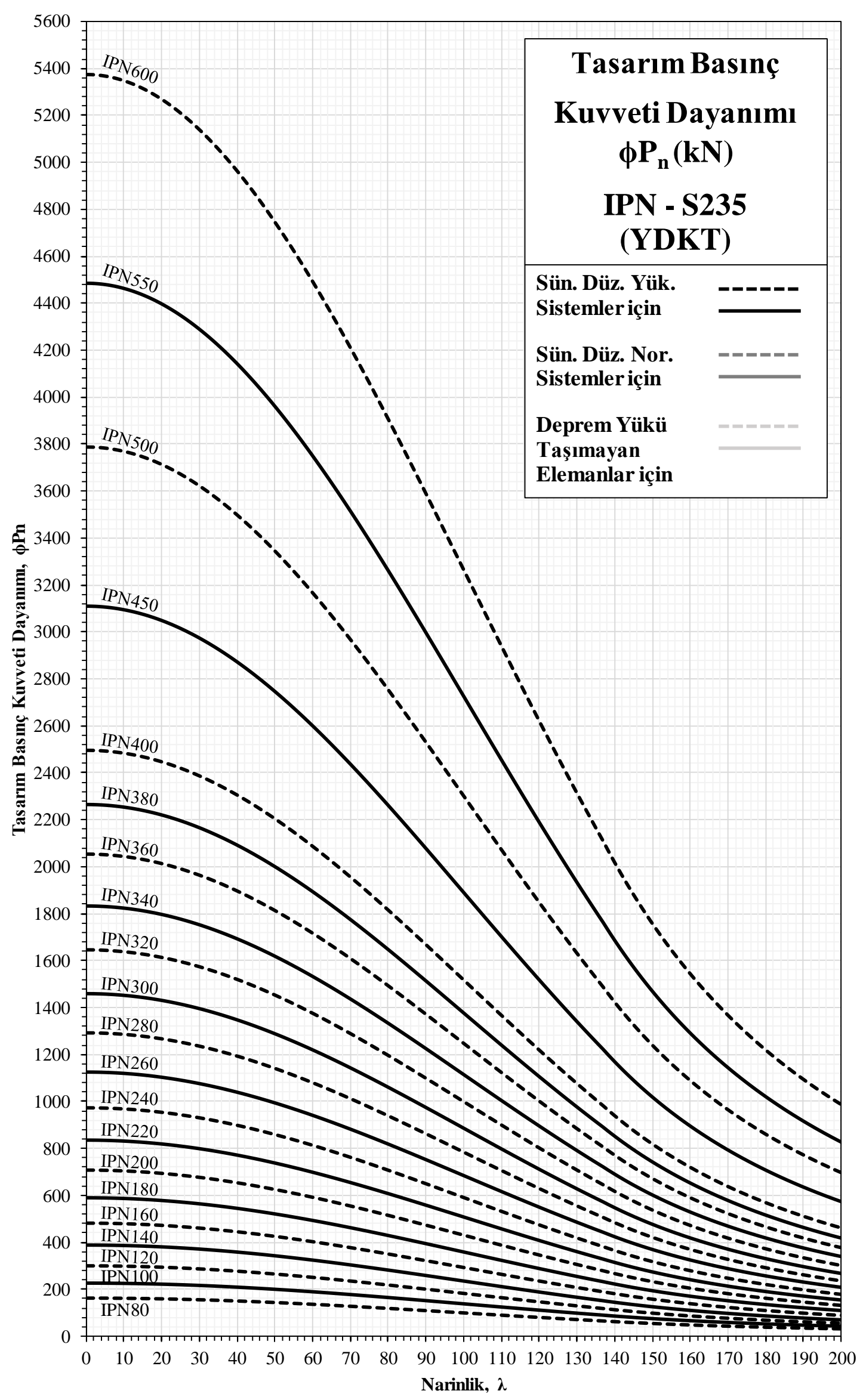

Şekil 11. S235 malzeme ve IPN enkesitlerine ait tasarım basınç kuvveti dayanımları 


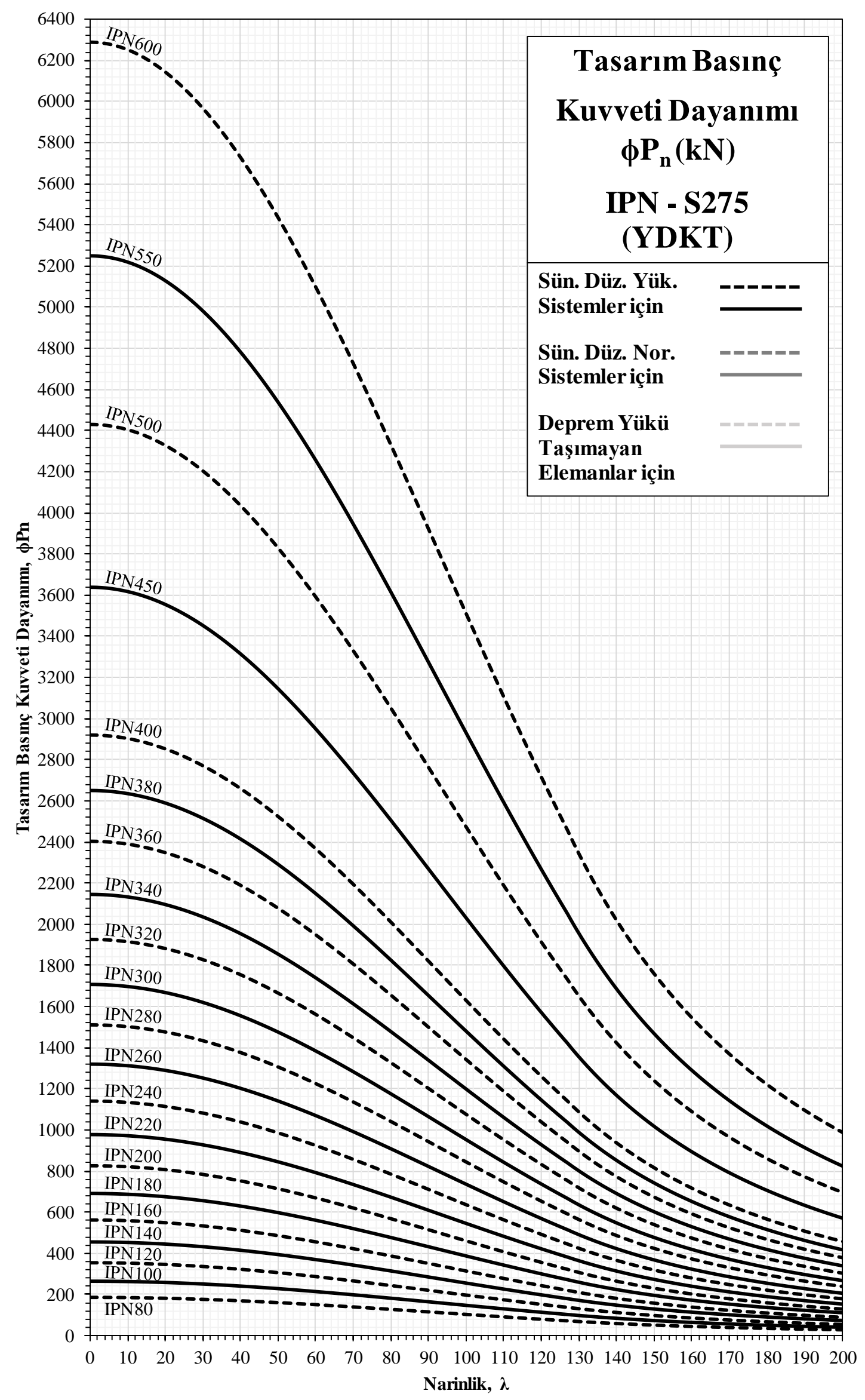

Şekil 12. S275 malzeme ve IPN enkesitlerine ait tasarım basınç kuvveti dayanımları 


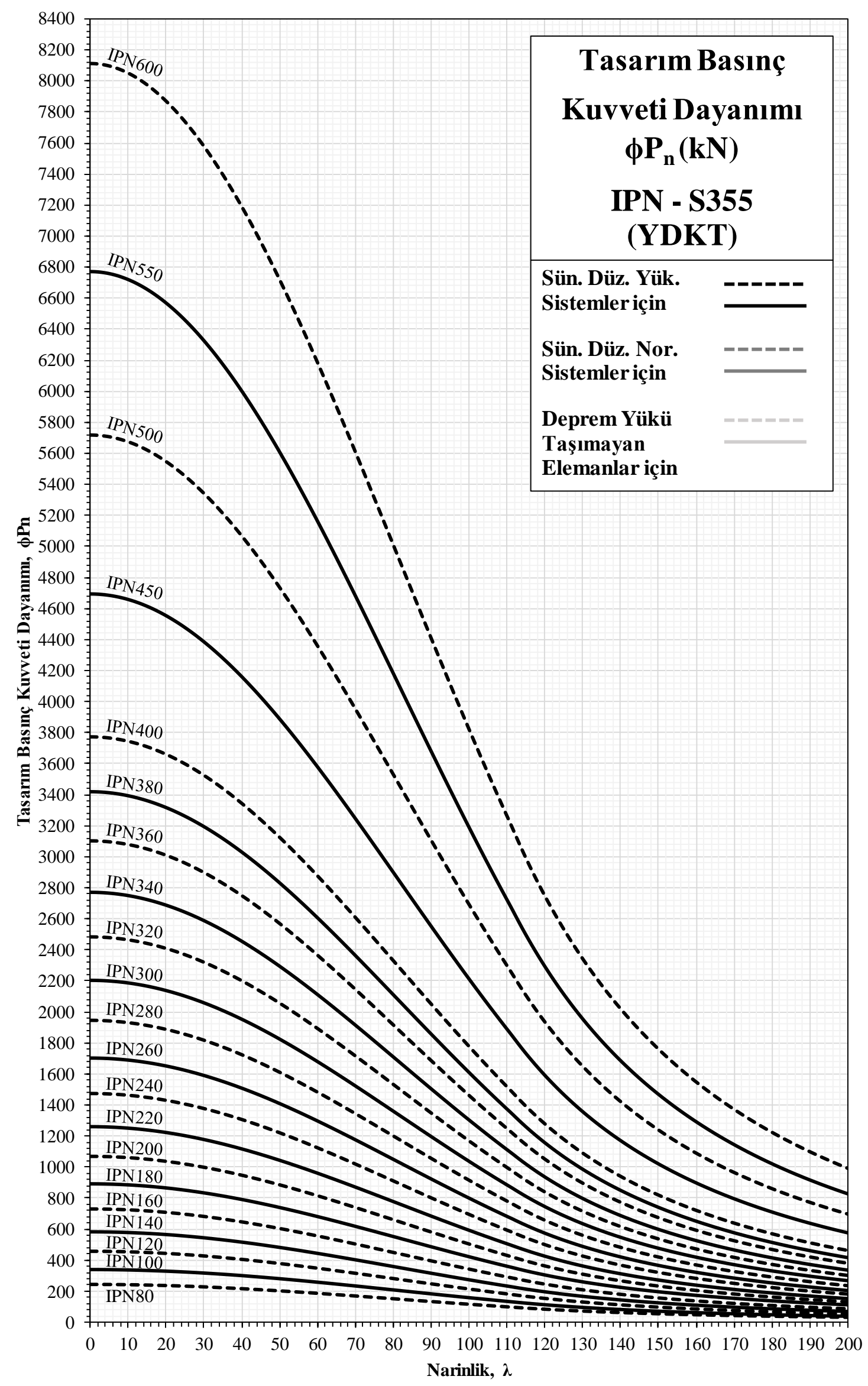

Şekil 13. S355 malzeme ve IPN enkesitlerine ait tasarım basınç kuvveti dayanımları 


\section{SAYISAL UYGULAMA}

$\mathrm{Bu}$ bölümde, sayısal uygulamalar üzerinden sunulan abakların nasıl kullanıldığı ve bu abaklar kullanılarak elde edilen sonuçların ÇYTHYE'de [6] tanımlanan ilgili formüller kullanılarak elde edilen sonuçlar ile karşılaştırması gerçekleştirilmiştir. Bu amaç ile aşağıda tanımlanan farklı malzeme sinıflarına (S235 ve S355), farklı enkesitlere (HEA300 ve IPE500) ve farklı etkin burkulma uzunluklarına (3000 ve $6000 \mathrm{~mm}$ ) sahip iki ucu basit mesnetli (mafsallı) basınç elemanlarının YDKT tasarım esaslarına göre eksenel tasarım basınç dayanımları iki farklı yönteme göre de belirlenmiş ve sonuçlar birbiri ile karşılaştırılmıştır.

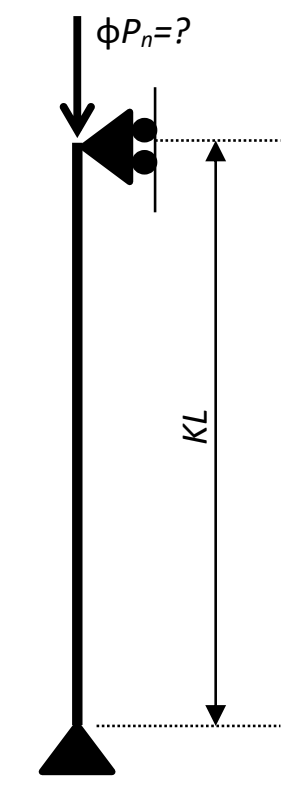

Şekil 14. Sayısal uygulama için kullanılan basınç elemanı

\section{A. SAYISAL UYGULAMA 1}

Malzeme sinıfi S235, enkesit HEA300, KL=3000 mm

\section{A. 1. ÇYTHYE'de [6] Tanımlanan Formüllerin Kulllanılması ile Tasarım Basınç Dayanımının Belirlenmesi}

Denklem (1) ve Denklem (2) kullanılarak enkesitin narin enkesit parçasına sahip olup olmadığı tayin edilir.

$$
\begin{aligned}
& \lambda=\frac{b_{f}}{2 t_{f}}=\frac{300}{2 \times 14}=10.7 \leq \lambda_{r}=0.56 \sqrt{\frac{E}{F_{y}}}=0.56 \sqrt{\frac{200000}{235}}=16.3 \quad \text { Narin olmayan başlik } \\
& \lambda=\frac{h}{t_{w}}=\frac{208}{8.5}=24.5 \leq \lambda_{r}=1.49 \sqrt{\frac{E}{F_{y}}}=1.49 \sqrt{\frac{200000}{235}}=43.5 \quad \text { Narin olmayan gövde }
\end{aligned}
$$

Narin enkesit parçasına sahip olmadığı için basınç yükü altında S235 malzeme sınıfından teşkil edilen HEA300 profilinde lokal burkulma gerçekleşmez. Dolayısıyla tasarım basınç dayanımının tayininde $A_{g}$ kayıpsız enkesit alanı kullanılmalıdır. 
Denklem (5)'de tanımlanan $F_{c r}$ kritik burkulma gerilmesinin hesaplanabilmesi için enkesitin narinlik değeri bulunarak burkulma şekli belirlenir.

$$
\frac{K L}{i_{\min }}=\frac{3000}{74.9}=40 \leq 4.71 \sqrt{\frac{E}{F_{y}}}=4.71 \sqrt{\frac{200000}{235}}=137 \text { elastik olmayan burkulma }
$$

Bu durumda, $F_{e}$ Euler burkulma gerilmesi ve $F_{c r}$ kritik burkulma gerilmesi aşağıdaki formüller kullanılarak hesaplanır.

$$
\begin{aligned}
& F_{e}=\frac{\pi^{2} E}{\left(\frac{K L}{i}\right)^{2}}=\frac{\pi^{2} \times 200000}{(40)^{2}}=1234 \mathrm{MPa} \\
& F_{c r}=\left(0.658^{\frac{F_{y}}{F_{e}}}\right) F_{y}=\left(0.658^{\frac{235}{1234}}\right) 235=217 \mathrm{MPa}
\end{aligned}
$$

Denklem (3) değeri $\Phi=0.90$ katsayısı ile çarpılarak tasarım basınç dayanımı elde edilir.

$$
\phi P_{n}=0.90 F_{c r} A_{g}=0.90 \times 217 M P a \times 11250 \mathrm{~mm}^{2} \times 10^{-3}=2197 \mathrm{kN}
$$

\section{A. 2. Önerilen Abakların Kullanılması ile Tasarım Basınç Dayanımının Belirlenmesi}

Enkesitin narinlik değeri hesaplanır ve ilgili abaktan tasarım basınç kuvveti dayanımı okunur.

$$
\frac{K L}{i_{\min }}=\frac{3000}{74.9}=40
$$




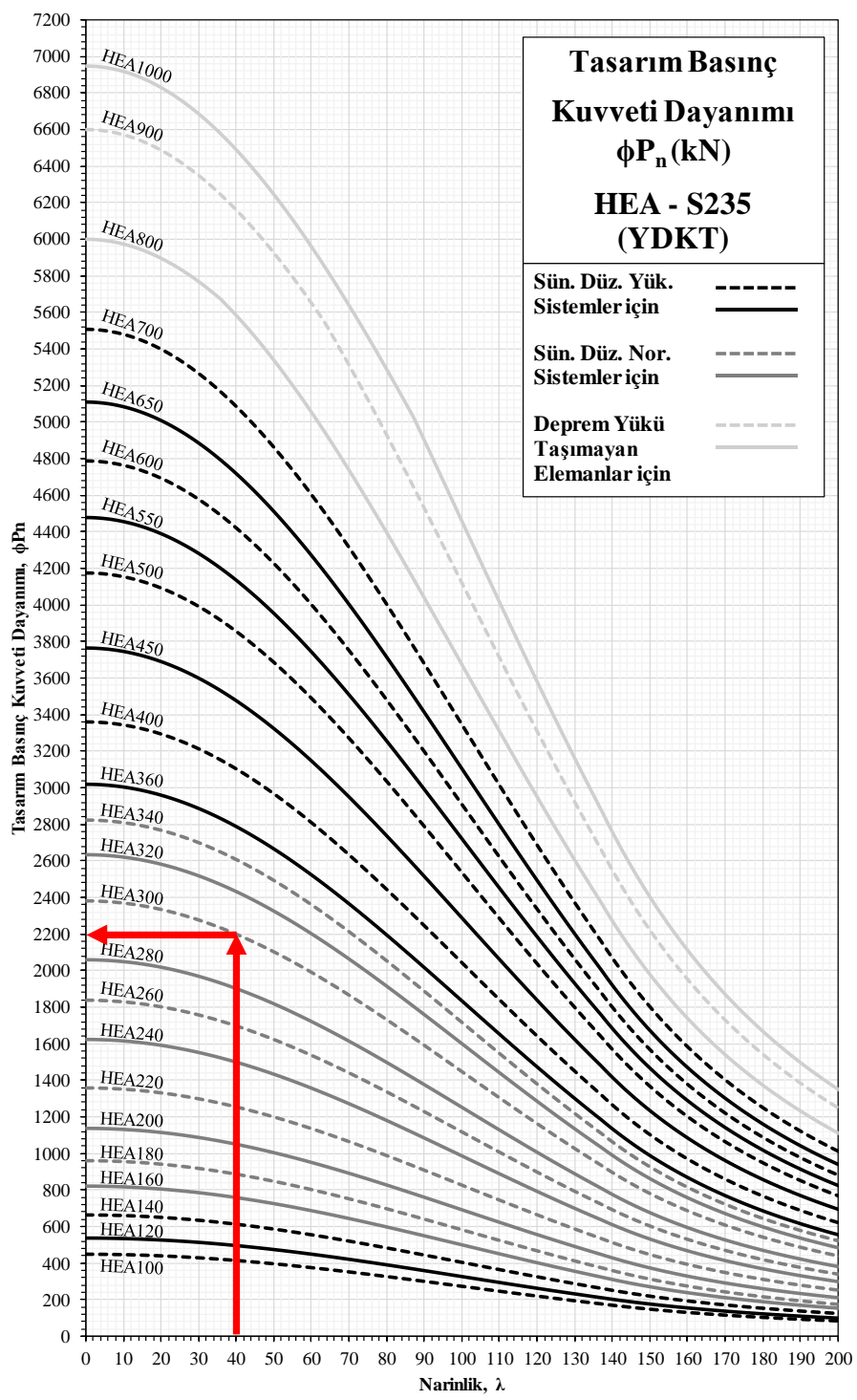

Şekil 15. Sayısal uygulama için kullanılan abak

Şekil 2'de verilen abak kullanılarak $\lambda=40$ değeri için HEA300 profilinin tasarım basınç dayanımı $\phi P_{n}=2200 \mathrm{kN}$ değeri okunur. ÇYTHYE' de [6] tanımlanan formüller ile elde edilen değer arasındaki fark \%0.1 olarak hesaplanır.

\section{B. SAYISAL UYGULAMA 2}

Malzeme sınıf1 S355, enkesit IPE500, KL=6000 mm

\section{B. 1. ÇYTHYE'de [6] Tanımlanan Formüllerin Kullanılması ile Tasarım Basınç Dayanımının Belirlenmesi}

Denklem (1) ve Denklem (2) kullanılarak enkesitin narin enkesit parçasına sahip olup olmadığı tayin edilir.

$\lambda=\frac{b_{f}}{2 t_{f}}=\frac{200}{2 \times 16}=6.3 \leq \lambda_{r}=0.56 \sqrt{\frac{E}{F_{y}}}=0.56 \sqrt{\frac{200000}{355}}=13.3 \quad$ Narin olmayan başlık 
$\lambda=\frac{h}{t_{w}}=\frac{426}{10.2}=41.8 \leq \lambda_{r}=1.49 \sqrt{\frac{E}{F_{y}}}=1.49 \sqrt{\frac{200000}{355}}=35.4 \quad$ Narin gövde

Narin gövde enkesit parçasına sahip olduğu için basınç yükü altında S355 malzeme sınıfından teşkil edilen IPE500 profilinde lokal burkulma gerçekleşebilir. Dolayısıyla tasarım basınç dayanımının tayininde $A_{e}$ etkin enkesit alanı kullanılmalıdır.

Denklem (5)'de tanımlanan $F_{c r}$ kritik burkulma gerilmesinin hesaplanabilmesi için enkesitin narinlik değeri bulunarak burkulma şekli belirlenir.

$$
\frac{K L}{i_{\min }}=\frac{6000}{43.1}=139>4.71 \sqrt{\frac{E}{F_{y}}}=4.71 \sqrt{\frac{200000}{355}}=112 \text { elastik burkulma }
$$

Bu durumda, $F_{e}$ Euler burkulma gerilmesi ve $F_{c r}$ kritik burkulma gerilmesi aşağıdaki formüller kullanılarak hesaplanır.

$$
\begin{aligned}
& F_{e}=\frac{\pi^{2} E}{\left(\frac{K L}{i}\right)^{2}}=\frac{\pi^{2} \times 200000}{(139)^{2}}=102 \mathrm{MPa} \\
& F_{c r}=0.877 F_{e}=0.877 \times 102=89 \mathrm{MPa}
\end{aligned}
$$

$A_{e}$, etkin alanın belirlenmesi,

$$
\lambda=\frac{h}{t_{w}}=\frac{426}{10.2}=41.8 \leq \lambda_{r} \sqrt{\frac{F_{y}}{F_{c r}}}=35.4 \sqrt{\frac{355}{89}}=70
$$

olduğu için

$$
b_{e}=b \text { ve dolayisiyla } A_{e}=A_{g}
$$

Denklem (4) değeri $\Phi=0.90$ katsayısı ile çarpılarak tasarım basınç dayanımı elde edilir.

$$
\phi P_{n}=0.90 F_{c r} A_{e}=0.90 \times 89 M P a \times 11550 \mathrm{~mm}^{2} \times 10^{-3}=925 \mathrm{kN}
$$

\section{B. 2. Önerilen Abakların Kullanııması ile Tasarım Basınç Dayanımının Belirlenmesi}

Enkesitin narinlik değeri hesaplanır ve ilgili abaktan tasarım basınç kuvveti dayanımı okunur.

$$
\frac{K L}{i_{\min }}=\frac{6000}{43.1}=139
$$




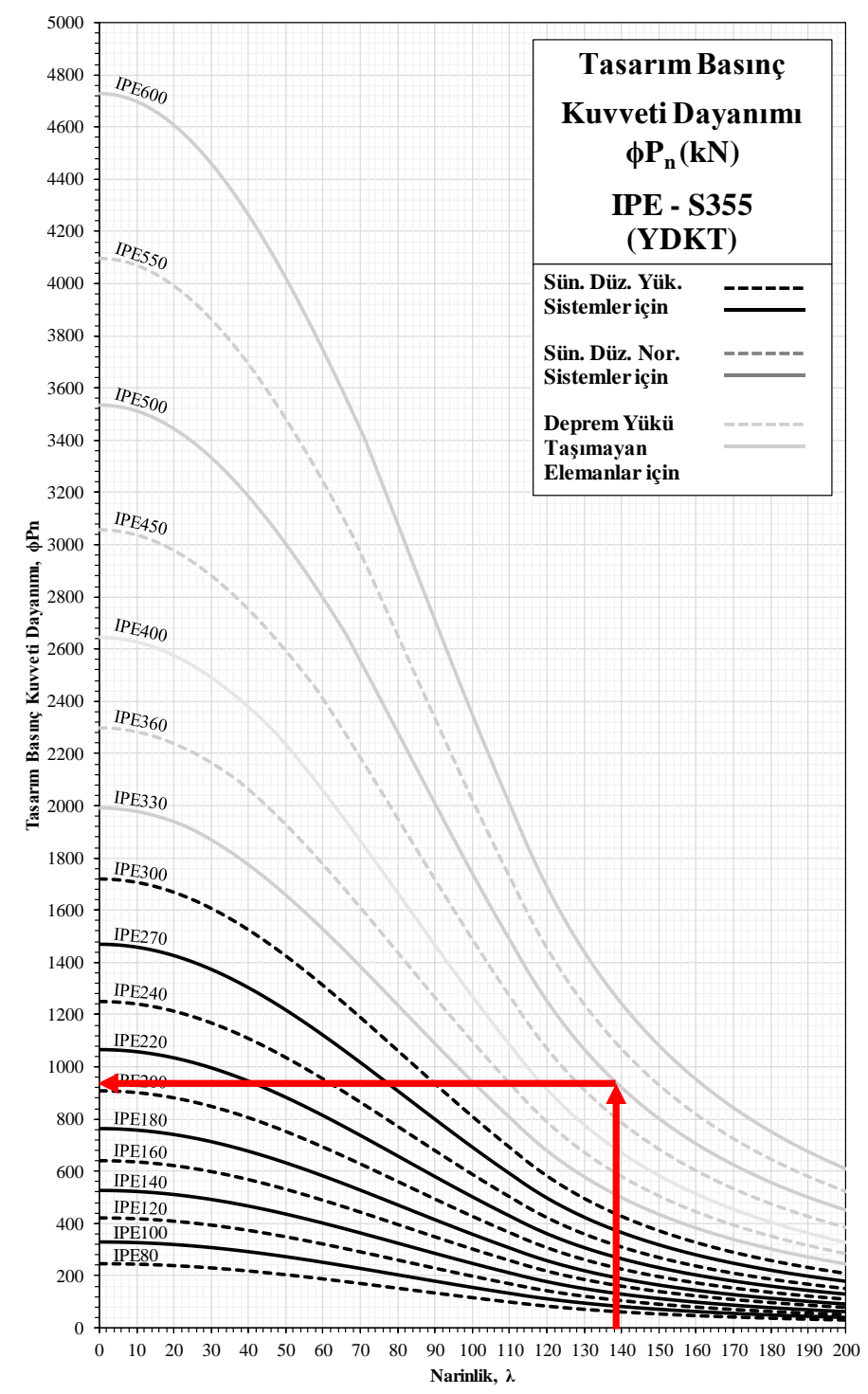

Şekil 16. Sayısal uygulama için kullanılan abak

Şekil 10'da verilen abak kullanılarak $\lambda=139$ değeri için IPE500 profilinin tasarım basınç dayanımı $\phi P_{n}=930 \mathrm{kN}$ değeri okunur. ÇYTHYE'de [6] tanımlanan formüller ile elde edilen değer arasındaki fark \%0.5 olarak hesaplanır.

\section{IV.SONUC}

Bu çalışma kapsamında yapısal tasarımcıların ÇYTHYE'de [6] tanımlanan YDKT esaslarına göre uygulamada en çok tercih edilen S235, S275 ve S355 malzeme sınıflarından teşkil edilmiş HEA, HEB, IPE ve IPN profillerinin eksenel basınç dayanımlarının narinliklerine göre değişimlerini gösteren yardımcı abaklar hazırlanmış ve yapısal tasarımcıların hizmetine sunulmuştur. Verilen sayısal uygulamalarda kullanılan abakların toplam iki adımda ve ÇYTHYE'de [6] tanımlanan formüller ile elde edilen değerler ile karşılaştırıldığında \%1'in altında hata oranı ile tasarım basınç dayanımlarını vermesi sunulan abakların çok kullanışlı ve güvenli olduğunu göstermektedir. 


\section{KAYNAKLAR}

[1] Specification for Structural Steel Buildings, ANSI/AISC 360-16, American Institute of Steel Construction (AISC), Chicago, 2016.

[2] Eurocode 3, Design of steel structures-part 1: general rules and rules for buildings, EN 19931:2004, European Standard, Comit Européen de Normalisation, Brussels, 2004.

[3] Design of Steel Structures, CSA S16:19, National Standard of Canada, Ontorio, (2019).

[4] Standard Specifications for Steel and Composite Structures, JSCE-2007, Japan Society of Civil Engineers, Tokyo, Japan, 2007.

[5] Çelik Yapıların Hesap ve Yapım Kuralları, TS 648, Türk Standartları Enstitüsü (TSE), Ankara, 1980.

[6] Çelik Yapıların Tasarım, Hesap ve Yapımına Dair Esaslar, ÇYTHYE 2018, Çevre ve Şehircilik Bakanlığı, Ankara, 2018.

[7] Steel Construction Manual, American Institute of Steel Construction (AISC), The Fifteenth Edition, Chicago, 2018.

[8] Steel Building Design: Design Data, The Steel Construction Institute, Berkshire, The British Construction Steelwork Association Ltd, London, 2011.

[9] Joints in Steel Construction: Simple Joints To Eurocode 3, The Steel Construction Institute, Berkshire, The British Construction Steelwork Association Ltd, London, 2014.

[10] Joints in Steel Construction: Moment-Resisting Joints To Eurocode 3, The Steel Construction Institute, Berkshire, The British Construction Steelwork Association Ltd, London, 2013.

[11] Çelik Yapıların Tasarım, Hesap ve Yapım Esaslarına Dair Yönetmelik Hakkında Uygulama Kılavuzu, Çevre ve Şehircilik Bakanlığı, Ankara, 2017. 